\section{Commentary: Is it safe? The marathon man meets pulmonary atresia with intact ventricular septum}

\author{
David M. Overman, MD
}

With dental instruments in hand, in one of the most excruciating scenes ever filmed, Sir Laurence Olivier repeatedly asks a baffled and terrified Dustin Hoffman: "Is it safe?"

Oh, what he would have given to know the answer... - The Marathon Man

Directed by John Schlesinger Robert Evans-Sidney Beckerman

Productions, October 8, 1976

Eitoku and colleagues ${ }^{1}$ have a deep understanding of and substantial experience with a complex anatomic substrate-pulmonary atresia with intact ventricular septum (PA/IVS) and what the authors term sinusoidal communications, also known as coronary-cameral fistulae or ventriculo-arterial connections. They afford readers an economical and incisive review as well as important surgical insights into this challenging subset of patients with PA/IVS.

That coronary anatomy is a critical factor in early and late outcomes for patients with PA/IVS has, of course, been known for some time. ${ }^{2}$ As the authors note, a recent multi-institutional report from Australia ${ }^{3}$ starkly reinforces this principle, as does the report by Cheung and colleagues, ${ }^{4}$

From the Division of Cardiovascular Surgery, Children's Minnesota, Mayo ClinicChildren's Minnesota Cardiovascular Collaborative, and Division of Cardiac Surgery, The Children's Heart Clinic, Minneapolis, Minn.

Disclosures: The author reported no conflicts of interest.

The Journal policy requires editors and reviewers to disclose conflicts of interest and to decline handling or reviewing manuscripts for which they may have a conflict of interest. The editors and reviewers of this article have no conflicts of interest.

Received for publication Oct 14, 2021; revisions received Oct 14, 2021; accepted for publication Oct 15, 2021; available ahead of print Oct 20, 2021.

Address for reprints: David M. Overman, MD, The Children's Heart Clinic, 2530 Chicago Ave, S, Suite 500, Minneapolis, MN 55404 (E-mail: doverman@chc-pa.org).

J Thorac Cardiovasc Surg 2022;163:2216-7

$0022-5223 / \$ 36.00$

Copyright (c) 2021 by The American Association for Thoracic Surgery

https://doi.org/10.1016/j.jtcvs.2021.10.021

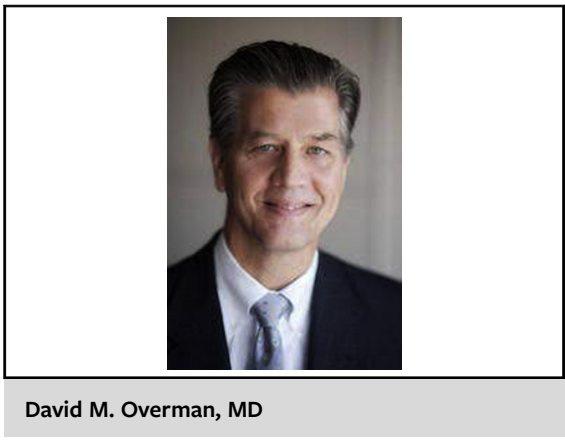

CENTRAL MESSAGE

Candidacy for ventricular

decompression is a critical deci-

sion in therapy for pulmonary

atresia with intact septum. Step-

wise decompression may in-

crease the safety and reliability of

this decision.

who reported $100 \%$ survival after single-ventricle palliation strategy in patients without right ventricle-dependent coronary circulation (RVDCC) compared with a mere $40 \%$ in those with RVDCC.

The most important question for the clinical team caring for a newborn infant with PA/IVS is this: Can the RV be decompressed, or will such decompression result in myocardial ischemia and death? The premium placed on getting it right could not be higher. If decompression can be safely undertaken, then the neonate has a chance at biventricular or one-and-one-half ventricle repair, with the associated phenomenon of RV growth, improved diastology, and the avoidance of long-term sequelae of Fontan circulation. Several other considerations have a bearing on this decision: tricuspid valve $z$ score, RV morphology, and pulmonary annular size and leaflet characteristics, but it is the coronary derangements that kill.

It is in this vein that the authors' staged decompression strategy finds its role, and this is the core content of their expert review. Using a semiquantitative calibration of the size of the communication across the pulmonary valve (achieved in this center by transarterial surgical valvotomy but in most cases translatable to the more commonly employed radiofrequency perforation and balloon valvotomy) and close monitoring of the resulting RV to left ventricle 
pressure ratio, the strategy described endeavors to gradually decompress the RV over time. Regression of the coronary sinusoids was achieved in roughly one-half of the patients, and this is important in light of what has been shown to be the deleterious effect of ventriculocoronary connections on left ventricular function. ${ }^{5,6}$

It is worth sounding a cautionary note that the authors make reference to techniques that warrant further scrutiny. Results of RV overhaul procedures have been mixed at best, with an important incidence of significant RV dysfunction. Aorta to RV shunting, described nearly 30 years ago by Laks and colleagues, ${ }^{7}$ remains a rare and relatively exotic approach to patients with RVDCC whose role and efficacy is obscure. The authors' decompression Fontan may very well improve the outlook of Fontan patients with chronic myocardial ischemia and/or blunt the progression of myocardial fibrosis. However it, too, requires further investigation to fully understand its place in an overall surgical strategy.

This article serves as an excellent guidepost to those embarking on the odyssey of divining the optimal strategy for a given patient born with PA/IVS. These are difficult and complex decisions with far-reaching consequences. The help offered by Eitoku and colleagues ${ }^{1}$ is welcome, indeed.

\section{References}

1. Eitoku T, Kasahara S, Baba K, Kotani Y. Impact of decompression of the right ventricle on the sinusoidal communications in pulmonary atresia and intact ventricular septum. J Thorac Cardiovasc Surg. 2022;163:2210-5.

2. Freedom RM, Anderson RH, Perrin D. The significance of ventriculo-arterial connections in the setting of pulmonary atresia with an intact ventricular septum. Cardiol Young. 2005; 15:447-68.

3. Elias P, Poh CL, du Plessis K, Zannino D, Rice K, Radford DJ, et al. Long-term outcomes of single-ventricle palliation for pulmonary atresia with intact ventricular septum: Fontan survivors remain at risk of late myocardial ischaemia and death. Eur J Cardiothorac Surg. 2018;53:1230-6.

4. Cheung EW, Richmond ME, Turner ME, Bacha EA, Torres AJ. Pulmonary atresia/ intact ventricular septum: influence of coronary anatomy on single ventricle outcome. Ann Thorac Surg. 2014;98:1371-7.

5. Gittenberger-de Groot AC, Sauer U, Bindl L, Babic R, Essed CE, Buhlmeyer K Competition of coronary arteries and ventriculo-arterial communications in pulmonary atresia with intact ventricular septum. Int J Cardiol. 1988;18:243-58.

6. Hausdorf G, Gravinghoff L, Keck EW. Effects of persisting myocardial sinusoids on left ventricular performance in pulmonary atresia with intact ventricular septum. Ann Thor Surg. 1993;56:1393-5.

7. Laks H, Gates RN, Grant PW, Drant S, Allada V, Harake B. Aortic to right ventricle shunt for pulmonary atresia and intact ventricular septum. Ann Thor Surg. 1995;59:342-7. 